\title{
Isolation from Urine of Two Serratia marcescens Strains Excreting a Diffusible Yellow Pigment
}

\author{
By JOAQUIM TRIAS, MIQUEL VIÑAS, JESUS GUINEA AND \\ JOSE G. LORÉN* \\ Department of Microbiology, School of Pharmacy, University of Barcelona, 08028 Barcelona, \\ Spain
}

(Received 26 March 1986; revised 22 October 1986)

\begin{abstract}
Two bacterial strains excreting a yellow pigment were isolated from human urine and identified as Serratia marcescens. The pigment was produced in the late exponential and early stationary phases of growth. Minimal media supplemented with tyrosine, phenylalanine, 3,4-dihydroxyphenylacetate or tryptophan, as well as complex media, induced pigment production. UVvisible spectra of the extracted pigment had peaks characteristic of 2-hydroxy-5-carboxymethylmuconate semialdehyde, produced from meta-cleavage of 3,4-dihydroxyphenylacetate by the enzyme 3,4-dihydroxyphenylacetate 2,3-dioxygenase (EC 1.13.11.15). This enzyme was active when the bacteria were grown under conditions promoting pigment production. The kinetics and factors affecting pigment production are also reported.
\end{abstract}

\section{INTRODUCTION}

Some strains of the genus Serratia can synthesize one of the two pigments specific for that genus among enterobacteria (Grimont \& Grimont, 1984; Williams \& Qadri, 1980). The most common, prodigiosin, is a red, non-diffusible pigment attached to the bacterial envelope (Purkayastha \& Williams, 1960; Viñas et al., 1983), and the other, pyrimine, is a rose-coloured diffusible pigment present only in the biotype A4 of $S$. marcescens (Grimont \& Grimont, 1984; Williams \& Qadri, 1980). Many clinical isolates of $S$. marcescens are unable to produce pigments (Ball et al., 1977; Clayton \& von Graevenitz, 1966; Lannigan \& Bryan, 1980; Ming-Jer Ding \& Williams, 1983). Some authors have correlated the absence of chromogenesis with the presence of R-plasmids in Serratia (Holland \& Dale, 1979; Platt \& Sommerville, 1981). Dauenhauer et al. (1984) have cloned the genes involved in prodigiosin biosynthesis, and have shown that they are not exclusively contained on plasmids. We present here the characterization of two $S$. marcescens strains isolated from urine, which excrete a yellow pigment that to our knowledge has not previously been described in the family Enterobacteriaceae.

\section{METHODS}

Bacterial strains. S. marcescens ATCC 274 was used as a reference strain. Strains CY429 and CY918 were isolated from urine samples from the 'Hospital de la Santa Creu i de Sant Pau de Barcelona' and from the 'Institut Policlinic de Barcelona' respectively.

Classification and antibiotic susceptibility tests. Biochemical characterization of the strains was made following Farmer et al. (1985), Blazevic (1980) and Grimont \& Grimont (1984). Minimal inhibitory concentrations (MICs) were measured by the Sensititre (Gibco) system.

Influence of media on pigment production. Cystine Lactose Electrolyte Deficient (CLED), MacConkey and Mueller-Hinton agars were from Difco. Trypticase Soy agar (TSA) was from BBL. Minimal medium M70 has been described elsewhere (Grimont \& Grimont, 1984). GL mineral medium contained ( $\mathrm{g}^{-1}$ ) glucose, 2; ammonium citrate, $5 ; \mathrm{K}_{2} \mathrm{HPO}_{4}, 8 ; \mathrm{MgSO}_{4} .7 \mathrm{H}_{2} \mathrm{O}, 0.5 ; \mathrm{Fe}\left(\mathrm{NO}_{3}\right)_{3} .9 \mathrm{H}_{2} \mathrm{O}, 0.02$; and $\mathrm{NaCl}, 0.5$ (Lorén \& Guinea, 1978). Bacteria were maintained on TSA slants. The influence of aromatic compounds and amino acids (all at 
$0.1 \%$, w/v) on pigment production was determined in $5 \mathrm{ml} \mathrm{GL}$, in tubes $(18 \times 180 \mathrm{~mm})$. A $0.5 \mathrm{ml}$ portion of an overnight culture in GL was used as an inoculum.

Kinetics of pigment production. Strain CY429 was used to study the kinetics of pigment production in M70 medium with glucose $(0.2 \%, \mathrm{w} / \mathrm{v})$ and in $\mathrm{M} 70$ with glucose and tyrosine $(0.1 \%, \mathrm{w} / \mathrm{v})$. Flasks containing $95 \mathrm{ml}$ medium were inoculated with $5 \mathrm{ml}$ of an overnight culture in M70 containing glucose. Incubation was carried out at $30^{\circ} \mathrm{C}$ in a reciprocal shaker at 100 r.p.m. Growth was monitored as $\mathrm{OD}_{550}$ in an Uvikon 810 (Kontron) spectrophotometer. Bacteria were removed by centrifuging and pigment production was measured in the supernatant at $380 \mathrm{~nm}$.

Pigment characterization. Cultures grown in M70 containing glucose and tyrosine were harvested when $A_{380}$ was maximal (in the late exponential phase of growth). Cultures were centrifuged at $8000 \mathrm{~g}$ for $10 \mathrm{~min}$ and supernatants were adjusted to $\mathrm{pH} 2$ with $1 \mathrm{M}-\mathrm{HCl}$. The pigment was extracted three times with an equal volume of ethyl acetate, and the organic layer was washed once with distilled water. The pigment was then partitioned into the aqueous layer by the addition of $1 \mathrm{M}-\mathrm{NaOH}$. The partition procedure was repeated, and UV-visible spectra were determined under alkaline and acidic conditions (Adachi et al., 1964).

Enzyme activity. For the assay of 3,4-dihydroxyphenylacetate 2,3-dioxygenase (EC 1.13.11.15), yellow pigmented bacteria were grown in M70 containing glucose and tyrosine until the late exponential phase of growth. Strain ATCC 274 was grown on M70 containing tyrosine until the late exponential phase. Bacteria were harvested and then washed three times with $0.02 \mathrm{M}$-Tris/ $/ \mathrm{HCl}$ buffer $(\mathrm{pH} \mathrm{7.8)}$ by centrifugation at $8000 \mathrm{~g}$ for $10 \mathrm{~min}$. Cell pellets were resuspended in the same buffer $\left[5 \mathrm{ml}\left(\mathrm{g}_{\text {bacteria }}\right)^{-1}\right]$ and the cells were disrupted with a Labsonic 1510 (Braun) sonicator. The broken cells were centrifuged at $15000 \mathrm{~g}$ for $30 \mathrm{~min}$ to remove debris and the supernatant (crude extract) was used for the assay. Assays were carried out at $25^{\circ} \mathrm{C}$ according to Cooper \& Skinner (1980) and Sparnins et al. (1974). Crude extract $(0.3 \mathrm{ml})$ was mixed with $2.7 \mathrm{ml} 0.02 \mathrm{M}-\mathrm{Tris} / \mathrm{HCl}$ buffer $(\mathrm{pH} 7 \cdot 8)$. The reaction was started by the addition of $10 \mu 110 \mathrm{~mm}-3,4-$ dihydroxyphenylacetate. Oxygen consumption was measured by a Clark type electrode (Rank). For routine analysis the reaction was followed by measuring the formation of 2 hydroxy-5-carboxymethylmuconate semialdehyde at $380 \mathrm{~nm}$. The product of the reaction was extracted as described above and UV-visible spectra obtained from the yellow-pigmented strains and from ATCC 274 were compared with those obtained from the supernatant. All the procedures to obtain the crude extract were carried out at $4^{\circ} \mathrm{C}$. Protein was determined by the Lowry method with BSA (Sigma) as a standard.

\section{RESULTS}

Strains CY429 and CY918 were identified as $S$. marcescens (confirmation of this was kindly provided by Dr P. A. D. Grimont, Institut Pasteur, Paris, France, by using auxanograms based on 119 tests). The main biochemical differences between these strains and $S$. marcescens ATCC 274 are shown in Table 1. The yellow-pigmented strains failed to grow on tyrosine, phenylalanine and 3,4-dihydroxyphenylacetate, and there were differences in their susceptibility to amikacin, tetracycline and tobramycin. Pigment was formed on MacConkey, CLED, TSA and Mueller-Hinton agars but not on solidified M70 medium containing glucose. Colour appeared around non-coloured colonies. The colour was unstable and disappeared from the media after incubation for $4 \mathrm{~d}$. Only when the medium was supplemented with 3,4dihydroxyphenylacetate, tyrosine, phenylalanine or tryptophan was pigment formed after incubation for $48 \mathrm{~h}$; alanine, arginine, aspartate, cysteine, glutamine, glycine, histidine, isoleucine, leucine, methionine, proline, serine, threonine, valine, benzoate, catechol, 3,4-

Table 1. Differential characteristics of the yellow pigmented strains

$$
\begin{array}{llll}
\text { Test } & \text { CY429 } & \text { CY918 ATCC } 274
\end{array}
$$

Growth on:

Tyrosine

Phenylalanine

3,4-Dihydroxy-

phenylacetate

Tryptophan

$\mathrm{NaCl}(8.5 \%, \mathrm{w} / \mathrm{v})$

Pigment production

Yellow

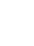

Prodigiosin

$\begin{array}{lll}- & - & + \\ - & - & + \\ - & - & + \\ \mathbf{w} & \text { w } & + \\ + & + & - \\ & & \\ + & + & +\end{array}$

+ , Growth; - no growth; w, weak growth. 


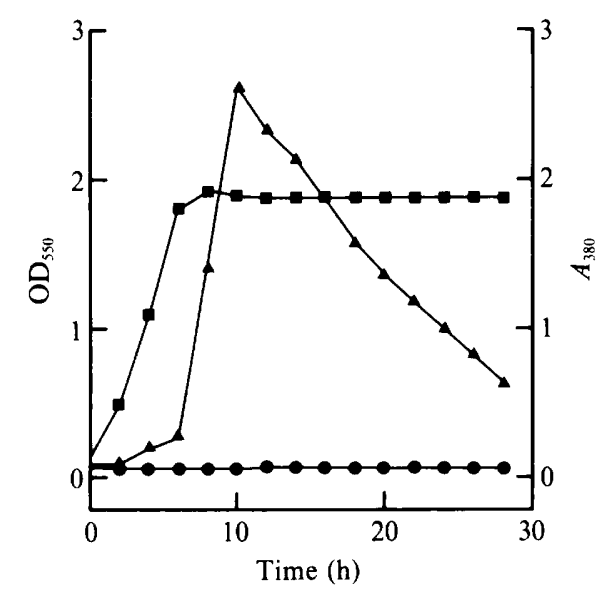

Fig. 1

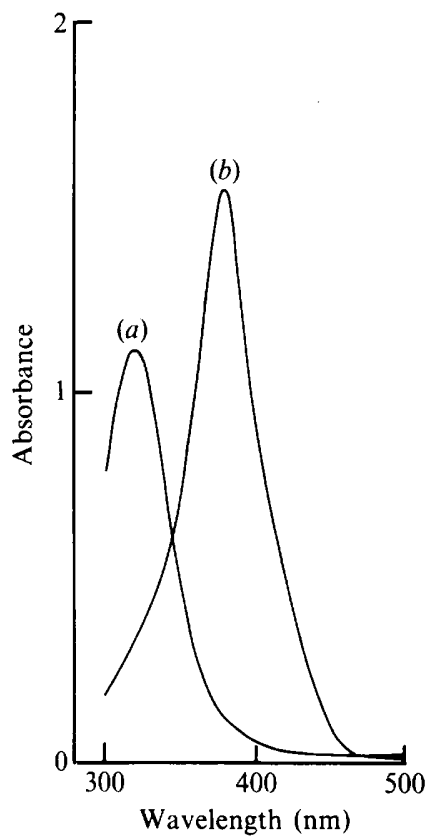

Fig. 2

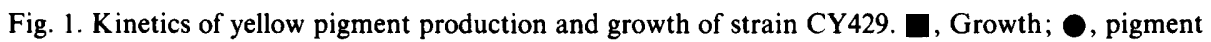
production in M70 with glucose; $\boldsymbol{\Lambda}$, pigment production in M70 with glucose and tyrosine.

Fig. 2. Spectra of the extracted yellow pigment in $(a)$ acidic and $(b)$ alkaline conditions.

Table 2. 3,4-Dihydroxyphenylacetate 2,3-dioxygenase activity of the strains grown in different media

Activity is expressed in nmol substrate used $\min ^{-1}(\mathrm{mg} \text { protein })^{-1}$. No activity was found when any of the strains were grown on glucose.

$\begin{array}{lcc}\text { Strain } & \overbrace{\begin{array}{c}\text { Glucose and } \\ \text { tyrosine }\end{array}}^{\text {Activity when grown on: }} \text { Tyrosine } \\ \text { ATCC 274 } & \text { ND } & 180 \\ \text { CY429 } & 17 & -* \\ \text { CY918 } & 16 & -*\end{array}$

ND, Not determined.

* The yellow pigmented strains did not grow on tyrosine.

dihydroxybenzoate, 2,5-dihydroxyphenylacetate and phenol failed to promote pigment production.

Pigment was produced in the late exponential and early stationary phases of growth (Fig. 1). In liquid, as on solid media, pigment disappeared quickly. UV-visible spectra of the extracted pigment revealed characteristic peaks at $380 \mathrm{~nm}$ in alkaline conditions and at $325 \mathrm{~nm}$ in acidic conditions (Fig. 2). These spectra are identical with those of 2-hydroxy-5-carboxymethylmuconate semialdehyde (Adachi et al., 1964), which is formed by the meta-cleavage of 3,4dihydroxyphenylacetate (Fig. 3) (Blackley et al., 1967; Sparnins et al., 1974) by the enzyme 3,4dihydroxyphenylacetate 2,3-dioxygenase (EC 1.13.11.15) (Ono-kamimoto, 1973; Sparnins et al., 1974). Table 2 shows the activities of this enzyme in crude extracts of $S$. marcescens 


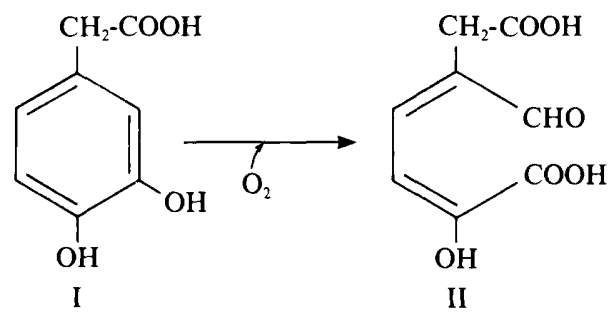

Fig. 3. meta-cleavage of 3,4-dihydroxyphenylacetate (I) by 3,4-dihydroxyphenylacetate 2,3-dioxygenase (EC 1.13.11.15), resulting in 2-hydroxy-5-carboxymethylmuconate semialdehyde (II).

ATCC 274 and the yellow pigmented $S$. marcescens CY429 and CY918. Extracts showed dioxygenase activity only when tyrosine was present in the medium. Strains maintained on TSA slants tended to lose the ability to produce pigment, and white strains obtained in this way were still unable to grow on tyrosine, phenylalanine and 3,4-dihydroxyphenylacetate.

\section{DISCUSSION}

Sugar fermentation tests, the ability to grow on different carbon and energy sources and other typical enterobacterial tests (Blazevic, 1980; Farmer et al., 1985; Grimont \& Grimont, 1984) demonstrated that strains CY429 and CY918 belong to $S$. marcescens. Growth on tyrosine as a sole carbon and energy source is a property which characterizes all strains of the genus Serratia studied by Grimont \& Grimont (1984). The ability to grow on 3,4-dihydroxyphenylacetate as a sole carbon and energy source is a positive characteristic of $S$. marcescens. However, strains CY429 and CY918 did not grow on minimal medium with these compounds as sole carbon and energy sources. Moreover, they did not grow on phenylalanine but grew in trypticase soy broth containing $8.5 \%(\mathrm{w} / \mathrm{v}) \mathrm{NaCl}$, both of which are variable characteristics of $S$. marcescens (Grimont \& Grimont, 1984).

S. marcescens CY429 and CY918 excreted a yellow diffusible pigment which to our knowledge has not been previously described in the Enterobacteriaceae. The two well known pigments in the genus Serratia are both typical secondary metabolites of this genus (Grimont \& Grimont, 1984; Williams \& Qadri, 1980). One of them, prodigiosin, has been extensively studied and its antibacterial and antifungal activities are well known (Torrey, 1983; Williams \& Qadri, 1980). In contrast, the yellow pigment excreted by CY429 and CY918 is a metabolite of a catabolic pathway involved in the energy metabolism of aromatic compounds. Thus, this yellow pigment is produced by primary metabolism, although its formation resembles that of secondary metabolites. 2-Hydroxy-5-carboxymethylmuconate semialdehyde is formed in some bacterial species (such as Escherichia coli, Pseudomonas putida, Acinetobacter spp.) as an intermediate metabolite of the catabolism of aromatic compounds with a side-chain larger than a $\mathrm{C}_{1}$ group (Blackley et al., 1967; Cooper et al., 1985; Cooper \& Skinner, 1980; Sparnins et al., 1974). The pigment is produced by the inducible enzyme 3,4-dihydroxyphenylacetate 2,3-dioxygenase which is characteristic of the homoprotocatechuate pathway for the catabolism of aromatic compounds (Blackley et al., 1967; Cooper \& Skinner, 1980; Sparnins et al., 1974).

The results concerning pigment production, the inability to grow on tyrosine, phenylalanine and 3,4-dihydroxyphenylacetate as a sole source of carbon and energy, and the ability to grow in the presence of $8.5 \%(\mathrm{w} / \mathrm{v}) \mathrm{NaCl}$, could indicate that strains CY429 and CY918 represent a new biotype of $S$. marcescens.

We thank Professor Robert P. Williams for critical reading of the manuscript and helpful suggestions. The authors thank Dr P. A. D. Grimont for confirmative identification of strains CY429 and CY918 and Dr G. Prats for supplying strain CY429. We are indebted to 'Fondo de investigaciones Sanitarias de la Seguridad Social' for providing a training fellowship (J.T.). 


\section{REFERENCES}

Adachi, K., TAKeda, Y., Senoh, S. \& Rita, H. (1964). Metabolism of $p$-hydroxyphenylacetic acid in Pseudomonas ovalis. Biochimica et biophysica acta 93, 483493.

Ball, A. P., McGhie, G. \& Geddes, A. M. (1977). Serratia marcescens in a general hospital. Quarterly Journal of Medicine, New Series 46, 63-71.

Blackley, E; R., Halvorson, H. \& Kurtz, W. (1967). The microbial production and some characteristics of D-carboxymethyl- $\alpha$-hydroxymuconic acid semialdehyde. Canadian Journal of Microbiology 13, 159-165.

Blazevic, D. J. (1980). Taxonomy, isolation and identification of Serratia. In The Genus Serratia, pp. 3-13. Edited by A. von Graevenitz \& S. J. Rubin. Boca Raton: CRC Press.

Clayton, E. \& von Graevenitz, A. (1966). Nonpigmented Serratia marcescens. Journal of the American Medical Association 197, 1059-1064.

COOPER, R. A. \& SkInNer, M. A. (1980). Catabolism of 3- and 4-hydroxyphenylacetate by the 3,4-dihydroxyphenylacetate pathway in Escherichia coli. Journal of Bacteriology 143, 302-306.

COOPER, R. A., Jones, D. C. \& PARrot, S. (1985). Isolation and mapping of Escherichia coli K12 mutants defective in phenylacetate degradation. Journal of General Microbiology 131, 2753-2757.

Dauenhauer, S. A., Hull, R. A. \& Williams, R. P. (1984). Cloning and expression in Escherichia coli of Serratia marcescens genes encoding prodigiosin biosynthesis. Journal of Bacteriology 158, 1128-1132.

FARMER, J. J., III, DAVIS, B. R., HICKMAN-BRENNER, F. W., McWhorter, A., HuNTley-Carter, G. P., Asbury, M. A., Biddle, C., WatheW-Grady, H. G., Elias, C., Steigerwalt, G. R., O'Hara, C. M., Morris, G. K., SMITH, P. B. \& BRENNER, D. J. (1985). Biochemical identification of new species and biograups of Enterobacteriaceae isolated from clinical specimens. Journal of Clinical Microbiology 21, 46-76.

Grimont, P. A. D. \& Grimont, F. (1984). Genus VIII. Serratia. In Bergey's Manual of Systematic Bacteriology, vol. 1, pp. 477-484. Edited by N. R. Krieg. Baltimore: Williams \& Wilkins.
Holland, S. \& Dale, J. W. (1979). The effect of resistance plasmids on pigmentation of Serratia marcescens. Microbios Letters 9, 85-89.

LANNIGAN, R. \& BRYAN, L. E. (1980). Increased frequency of acceptance of plasmidic deoxyribonucleic acid by non-pigmented strains of Serratia marcescens. Microbios Letters 13, 123-127.

LoRén, J. G. \& GuineA, J. (1978). Efecto de la concentracion de glucosa sobre la biosintesis de prodigiosina por Serratia marcescens. Revista española de fisiologia 34, 247-252.

Ming-Jer Ding \& Williams, R. P. (1983). Biosynthesis of prodigiosin by white strains of Serratia marcescens isolated from patients. Journal of Clinical Microbiology 17, 476-480.

Ono-Kamimoto, M. (1973). Studies on 3,4-dihydroxyphenylacetate 2,3-dioxygenase. I. Role of iron, substrate binding, and some other properties. Journal of Biochemistry 74, 1049-1059.

Platt, D. J. \& Sommerville, J. S. (1981). Pigmentation stability and the influence of RP4 on pigmentation in S. marcescens. Society for General Micrabiology Quarterly 8, 100-101.

Purkayastha, M. \& Williams, R. P. (1960). Association of pigment with the cell envelope of Serratia marcescens. Nature, London, 187, 349-350.

SPaRnins, V. L., Chapman, P. J. \& Dagley, S. (1974). Bacterial degradation of 4-hydroxyphenylacetic acid and homoprotocatechuatic acid. Journal of Bacteriology 120, 159-167.

TORREY, S. (1983). Prodigiosin by Serratia marcescens R2. In Microbiological Synthesis. Recent Advances, pp. 44-45. Edited by S. Torrey. Park Ridge, New Jersey: Noyes Data Corp.

Viñas, M., LoReN, J. G. \& GuINEA, J. (1983). Particulate-bound pigment of Serratia marcescens and its association with cellular envelopes. Microbios Letters 24, 19-26.

WIlliams, R. P. \& QADRI, S. M. H. (1980). The pigment of Serratia. In The Genus Serratia, pp. 3175. Edited by A. von Graevenitz \& S. J. Rubin. Boca Raton: CRC Press. 